\title{
A quick laboratory method for assessment of blood penetration and splash resistance of PPE fabrics during the COVID-19 pandemic situation
}

\section{R. K. Chaurasia}

Bhabha Atomic Research Centre, Mumbai, India

U. Yadav

Bhabha Atomic Research Centre, Mumbai, India

N. N. Bhat

Bhabha Atomic Research Centre, Mumbai, India

B. K. Sapra ( $\square$ bsapra@barc.gov.in )

Bhabha Atomic Research Centre, Mumbai, India

\section{Research Article}

Keywords: PPE fabrics, COVID-19, laboratory set up, synthetic blood penetration, splash resistance, radiation-sterilisation.

Posted Date: May 27th, 2020

DOl: https://doi.org/10.21203/rs.3.rs-31826/v1

License: (9) This work is licensed under a Creative Commons Attribution 4.0 International License. Read Full License

Version of Record: A version of this preprint was published at Transactions of the Indian National Academy of Engineering on January 29th, 2022. See the published version at https://doi.org/10.1007/s41403-021-00318-8. 


\section{Abstract}

In the current outbreak of COVID-19, healthcare facilities are hit by a shortage of supply of Personal Protective Equipments (PPE) owing to extensive local and global demands and restrictions on their import or export. To circumvent this, trials with several indigenous materials suitable to qualify for PPEs and sterilisation techniques for their reuse are being carried out. Prior to their commercialisation or reuse, it is imperative to evaluate the resistance of the PPE-fabrics against penetration of synthetic blood under applied pressure in the range of $40-300 \mathrm{mmHg}$ as per test standards. Generally, two types of tests are recommended, namely, the Penetration Test and Splash Resistance Test, the former being more stringent. While the final certification of PPEs is carried out by authorised agencies, a first impression quick estimate of the choice of fabric can be made by using a simple laboratory set up. This study describes set ups developed in the laboratory to carry out these tests. Evaluation of the fabrics, post-gamma irradiation, was also carried out. Microscopic examinations were performed to investigate radiation induced structural changes in fabrics showing degraded performance. The developed set ups are useful for selection of fabrics and to assess the feasibility of reuse of PPEs, which is the need of the hour in this pandemic situation.

\section{Introduction}

In the current scenario of COVID-19 pandemic, a large number of Health Care Professionals (HCPs) are being engaged for medical, clinical and logistics managements. The chances of accidental exposures have increased, with possibility of contact with pathogenic organisms. Major routes of pathogen entries are inhalation and/or ingestion of aerosols, open skin lesions, subcutaneous injections through needle and scratches with contaminated objects $(1,2)$. Some crucial viral infections like recent outbreaks of ebola virus, norovirus and Middle East Respiratory Syndrome (MERS) corona virus have already been reported for their association with occupational infections (3-5).

To avoid/minimize the risk of accidental exposure to pathogenic organisms, it is mandatory that the HCPs wear suitable Personal Protective Equipment (PPE) at workplaces when dealing with infected patients. Current scenario demands quality controlled, rapid production of Personal Protective Equipments (PPEs) like face masks, aprons, gloves etc. PPEs act as a protective barrier between the patients and the HCPs, by avoiding penetration of body fluid (blood, saliva, plasma, serum, urine, spit, etc.) which may ooze or spurt-out from the patient's body at a pressure ranging from 60 to $300 \mathrm{~mm} \mathrm{Hg}$ (6). The spurted body fluids may carry various kinds of contagious microorganisms like viruses, bacteria, fungal-spores and other parasites. Among these, the viruses are critical and seek special attention as they are small in size (Nanometre-range) and become the limiting criteria for the selection of appropriate fabric for the PPEs (7). 
Selection of suitable PPE material is a crucial step for PPE manufacturing industries. ISO 16603 and ASTM F1670 are the most followed standards to categorise these materials, as per their performance, into different classes, which can be used in various medical/clinical scenarios $(8,9)$. Synthetic Blood Penetration Resistance Test (SBPRT) is a standard, most crucial and widely used criteria for qualification of the fabric. This involves assessing the resistance of the fabric against an applied fluid (synthetic blood) in the pressure range of $60-160 \mathrm{mmHg}$ for varying time durations (5-30 mins or more) $(10,11)$. Detection of penetrated fluid, downstream of the test sample, acts as qualifying indicator of the test.

In this pandemic crisis, small laboratory scale test setups, with existing laboratory equipment, were developed to assess the choice of fabric having potential to qualify for PPE manufacturing. This simple setups can be easily adapted by any lab equipped with basic tissue culturing facility and can be effectively used for performance evaluation of PPEs made from new materials, or those subjected to sterilisation methods for their possible reuse.

\section{Materials And Methods}

\section{Study Plan:}

This study includes, development of test set-up with existing laboratory equipments to evaluate performances of 11 PPE-fabrics against penetration of Synthetic Blood Equivalent (SB) at various pressures ranging from $40-300 \mathrm{~mm} \mathrm{Hg}$ applied fluid pressure, before and after radiation sterilization (30 kGy, gamma radiation). Of the 11 fabrics, three were subjected to splash resistance test. As a mechanistic approach, radiation induced structural changes in the fabrics were examined under fluorescence and bright field microscope.

\section{Test Materials/Fabrics:}

Limited commercial information about composition of the material used in these fabrics was available to us; the maximum fraction of most fabrics is Polyethylene/Polystyrene/Polypropylene. All the fabrics were non-woven type with multiple internal layers and hot-spot press patterns. However, fractions and densities of Polyethylene/Polystyrene/Polypropylene were not same in all fabrics. Some samples of fabrics irradiated using gamma radiation to a dose of $30 \mathrm{kGy}$ were also received to study the effect of gamma sterilisation on the PPE material.

\section{Simulation of Test Set-up for SBPRT:}

We have put together a working set-up with existing laboratory instruments while following the guidelines of ISO 16603 ASTM F1670 and JIST 8060 and 8122 with minor modifications without compromising on physical parameters of the test standards. The set-up was built with a conventional biological media filtration assembly, as shown in figure -1. It included two vented cylindrical chambers, which could be sealed airtight to sustain planned pressure levels. These two chambers were connected at the middle region of the assembly (which was designed to hold the filter) through a gauge. The circular piece of 
fabric, of diameter $\sim 5 \mathrm{~cm}$ of the test material was placed over this filter holder. The upper surface of the fabric was layered with $20 \mathrm{ml}$ of SB and this chamber was connected with a pressure unit of the sphygmomanometer to create and measure air pressure in the chamber. It was ensured that fluid column height of SB was very small $(\sim 1 \mathrm{~cm})$ so that its gravitation pressure is negligible compared to the applied pressure. SB was prepared in the lab, having physical attributes similar to Synthetic blood (mixture of polysaccharide, buffer and dye, without preservative). The whole set-up was kept in a 2.5 -litre beaker to support it and collect the dripping fluid.

\section{Simulation of Test Set-up for Splash Resistance Test:}

This test set-up comprised of a circular fabric holder and an injector placed at a distance of $30 \mathrm{~cm}$ as shown in figure-2. The fabric holder was mounted on a lead block for stability and placed in a beaker to collect the dripping liquid. The injector was placed at an appropriate height with the help of a height adjustable stand. In one run, $8 \mathrm{ml}$ of SB fluid was injected on the fabric sample and the penetrated fluid was detected on the other side of the fabric.

\section{Detection of Synthetic Blood Penetrating through the Fabric}

For both the above-mentioned tests, the penetrated SB was detected at 3 levels; 1) visual detection, 2) detection by absorbent paper - after applying the planned fluid pressure, absorbent paper was swiped on to the downstream surface, SB spot created if any, was examined visually and 3) detection by magnifying lens - third level of detection was carried out with magnifying hand lens (for both penetrated droplets and spots created on absorbent paper).

\section{Microscopic Examinations of Radiation Induced Structural Changes in Fabrics:}

Fabrics were cut into pieces of $2 \mathrm{~cm} \mathrm{x1} \mathrm{cm} \mathrm{dimensions,} \mathrm{sandwiched} \mathrm{between} \mathrm{the} \mathrm{glass} \mathrm{slide} \mathrm{and} \mathrm{a} \mathrm{cover}$ glass and ends were sealed with rubber cement (figure-3) to prepare them for examination under a microscope. Total 6 samples were observed and analysed, 3 before and 3 after radiation sterilization (30 kGy). Structural changes/examination of voids, were carried out at $100 \mathrm{X}$ and $400 \mathrm{X}$ magnifications.

\section{Results And Discussion}

\section{Performance Evaluations by Synthetic Blood Penetration Resistance Test:}

A vertical setup has been assembled with culture media filtration assembly connected to a pressured unit of medical sphygmomanometer as shown in Figure-4. The pressure was exerted manually from chamberA with the help of a rubber bulb. Setup was first tested with non-porous material, nitrile glove material for its pressure holding ability and leakages, if any. It was confirmed that, pressure once exerted persists without any leakage up to tested pressure of $300 \mathrm{mmHg}$. Our setup qualified for precise pressure creation and holding criteria without any leakage. 
The fabric samples A-K were subjected to SBPR-test in a pressure range of $0-300 \mathrm{mmHg}$ or up to the breaking/leaking pressure point. The fabrics were first exposed to the fluid for $5 \mathrm{~min}$ at atmospheric pressure. Pressure was applied in an increasing order in steps of $20 \mathrm{mmHg}$ for 5 mins at each pressure point. The results of the test w.r.t. the sustained pressure, the corresponding JIST 8122 classification and their utility classes are given in Table 1. The effect of radiation in degrading/deterioration of Fabrics $A$ and $B$ is also evident from this Table. For Fabric-A, the pressure holding ability decreased from 80 to 60 $\mathrm{mmHg}$ and Fabric-B lost its ability to hold $40 \mathrm{mmHg}$ fluid pressure post-irradiation. The Fabrics $\mathrm{C}, \mathrm{I}, \mathrm{J}$ and $\mathrm{K}$ did not reach the breaking point even up to a pressure of $300 \mathrm{~mm} \mathrm{Hg}$, before and after radiation sterilization. It was observed that Fabrics-D, E, F, G and $\mathrm{H}$ were able to sustain at atmospheric pressure but could not resist at $40 \mathrm{mmHg}$ fluid pressure, started leaking heavily, both before and after radiation sterilization. For all fabrics, the test was repeated three times to confirm the results.

For Fabrics-I and J, resistances were also tested at the fabric joints (sewed and taped). It was observed that, at improperly taped joints, some creases trapped inside the taping line acted as a passage for fluid to reach to the sewed line and penetrate through it (Figure-5). However, in case of samples with properly taped joints, the highest pressure was sustained by the fabric. It is emphasized that quality of taping plays a crucial role irrespective of performance of the fabric as a whole.

\section{Method of detection of Fluid Penetration Through the Fabric:}

Fluid penetration through the fabric was detected at three levels, first level of detection was visual through naked eye, following ISO 16603 protocols. To enhance sensitivity of the detection, swipe test was performed, wherein leaked surface was swiped with absorbent paper and spot created on it, if any, was observed to confirm leakage (adapted from Shimashaki et al 2017) (12). The test was added assuming that micro amount of fluid penetrating through the fabric may not be visible by naked eye but can be detected by swipe test. Presence or absence of spots on absorbent paper was further confirmed by observation under a magnifying hand-lens. These levels of detection helped us to define cut off pressure holding point for each tested fabric.

Figure 6 shows visual observations of the samples showing the leakages through the fabric at varying pressure points, both before and after irradiation. On the other hand, Figure 7, shows the three levels of detection adopted to confirm the leakage at the breaking point pressure.

\section{Fabric Evaluations by Splash Resistance Test:}

Performances of fabrica-A, B and C were further evaluated by Synthetic Blood Splash Resistance Test using the test setup developed (Figure-8). A $\sim 2 \mathrm{~cm}$ diameter of fabric sample was placed in the fabric holder and $8 \mathrm{ml}$ of SB was splashed on it at a pressure range of $280-300 \mathrm{mmHg}$ from a distance of 30 $\mathrm{cm}$. This was repeated three times on each sample so that effectively $24 \mathrm{ml}$ of SB was splashed on each tested fabric sample. As per ISO reference protocol $2 \mathrm{ml}$ of SB should be splashed on the test fabric, with $60-160 \mathrm{mmHg}$ pressure range from a distance of $30 \mathrm{~cm}$ (13). No fluid penetration was detected for all the three fabrics (Figure-9). Since the fabrics did not leak at the higher pressure ranges and for large 
volumes over longer duration, there was no need to evaluate their performances at lower pressure ranges. All three levels of detections were followed as described earlier and are depicted in Figure-10.

\section{Microscopic Examination of Fabrics:}

To observe structural changes induced in the fabrics by radiation sterilization, microscopic examinations were carried out. It was observed that post irradiation, number and size of voids increased in the mesh region of the fabrics $A$ and $B$, however not much detectable changes were observed in pressed regions (figure-11). This increased number and size of voids was responsible for decreased fluid pressure holding ability. No structural changes were observed (both in mesh and pressed regions) in fabric-C, before and after radiation sterilization as illustrated in figure-12. Information gathered by microscopic examination of fabric-A, B and C was in accordance with our SBPRT findings and it provided supplementary structural and mechanistic support to our observations.

\section{Conclusion}

Simple test set ups have been put together using existing laboratory instruments to evaluate the blood penetration resistance of various fabrics of PPEs. These can help in a quick screening and selection of fabric materials without compromising on parameters of the tests. These set ups can be adopted in any research/medical facility for rapid performance evaluation of PPE-fabrics during any emergency situation like the current COVID19 pandemic. Such a setup will help local manufacturers to produce PPEs in adverse situations without compromising on the safety parameters.

Pressure holding ability of the fabric is an intrinsic property of the material, that can not be changed. However, when the PPEs are tailored, the quality of the sewing and taping at the joints is utmost important. As observed in this study, the pressure holding ability of the poor joints was considerably reduced, much below the holding ability of the same fabric. An appropriate tailoring and taping to achieve proper sealing of the joints can improve the performances of these PPEs.

\section{Declarations}

\section{Acknowledgements:}

The authors of the article would like to thank, Dr.P.K. Pujari, Associate Director, Radiation Chemistry and Isotope Group, BARC and Dr. Y.K. Bhardwaj, RTDD, BARC for their help in providing the samples and carrying out the irradiations respectively. The authors also greatly acknowledge the support and motivation given by R.M. Suresh Babu, Associate Director, Health, Safety and Environment Group, during the course of this work.

\section{Conflict of Interests:}

Authors declare that, they do not have any conflict of interests. 


\section{Source of Funding:}

All required infrastructure and funds were offered by the Host institute.

\section{Additional information:}

None

\section{References}

1. Coelho, Ana Cláudia, and Juan García Díez. "Biological risks and laboratory-acquired infections: a reality that cannot be ignored in health biotechnology." Frontiers in bioengineering and biotechnology3 (2015): 56.

2. Wurtz, N., et al. "Survey of laboratory-acquired infections around the world in biosafety level 3 and 4 laboratories." European Journal of Clinical Microbiology \& Infectious Diseases8 (2016): 1247-1258.

3. Kilmarx, Peter H., et al. "Ebola virus disease in health care workers-Sierra Leone, 2014." Morbidity and mortality weekly report63.49 (2014): 1168.

4. Saegeman, Veroniek, et al. "Tracing delays in infection control measures in a nosocomial norovirus outbreak." Journal of Hospital Infection3 (2015): 286-287.

5. Hsieh, Ying-Hen. "2015 Middle East respiratory syndrome coronavirus (MERS-CoV) nosocomial outbreak in South Korea: insights from modeling." PeerJ3 (2015): e1505.

6. Jones, Rachael M., et al. "A systematic risk-based strategy to select personal protective equipment for infectious diseases." American journal of infection control1 (2020): 46-51.

7. Nikiforuk, Aidan M., et al. "Challenge of liquid stressed protective materials and environmental persistence of ebola virus." Scientific reports1 (2017): 1-9.

8. ISO 16603: 2004. "Clothing for protection against contact with blood and body fluids-Determination of the resistance of protective clothing materials to penetration by blood and body fluids-Test method using synthetic blood."

9. ASTM F1670/F1670M- "Standard Test Method for Resistance of Materials Used in Protective Clothing to Penetration by Synthetic Blood." (2017).

10. JIS, T. "8122 (2007) Protective clothing for protection against hazardous biological agentsClassification and test methods." Japanese Industrial Standards.

11. JIS, T. "8060 (2007) Clothing for protection against contact with blood and body fluidsDetermination of the resistance of protective clothing materials to penetration by blood and body fluids-Test method using synthetic blood." Japanese Industrial Standards.

12. Shimasaki, Noriko, Katsuaki Shinohara, and Hideki Morikawa. "Performance of materials used for biological personal protective equipment against blood splash penetration." Industrial health6 (2017): 521-528. 


\section{Table}

Table-1: Illustration of maximum tolerance pressure of fabric-A-K before and after radiation sterilization and its JIST8122 classification and utility.

\begin{tabular}{|c|c|c|c|c|}
\hline \multirow[b]{2}{*}{$\begin{array}{l}\text { Fabric } \\
\text { Sample }\end{array}$} & \multicolumn{2}{|c|}{ Tolerance Pressure (mmHg) } & \multirow[b]{2}{*}{$\begin{array}{l}\text { JIST8122 } \\
\text { classification }\end{array}$} & \multirow[b]{2}{*}{$\begin{array}{l}\text { Performance of the } \\
\text { material }\end{array}$} \\
\hline & $\begin{array}{l}\text { Before Radiation } \\
\text { Sterilization }\end{array}$ & $\begin{array}{l}\text { After Radiation } \\
\text { Sterilization }\end{array}$ & & \\
\hline A & 80 & 60 & Class-3 & Moderate \\
\hline B & 40 & $<40$ & Class-1 & Low \\
\hline $\mathrm{C}$ & $>300$ & $>300$ & Class- 6 & High \\
\hline $\mathrm{D}$ & $<40$ & $<40$ & Class-1 & Low \\
\hline $\mathrm{E}$ & $<40$ & $<40$ & Class-1 & Low \\
\hline $\mathrm{F}$ & $<40$ & $<40$ & Class-1 & Low \\
\hline $\mathrm{G}$ & $<40$ & $<40$ & Class-1 & Low \\
\hline $\mathrm{H}$ & $<40$ & $<40$ & Class-1 & Low \\
\hline I & $>300$ & $>300$ & Class- 6 & High \\
\hline I (joint) & $\begin{array}{l}<40 \text { (improperly } \\
\text { taped) } \\
>300 \text { (properly } \\
\text { taped) }\end{array}$ & $\begin{array}{c}<40 \text { (improperly } \\
\text { taped) } \\
>300 \text { (properly } \\
\text { taped) }\end{array}$ & Class-1 & Low \\
\hline $\mathrm{J}$ & $>300$ & $>300$ & Class- 6 & High \\
\hline $\mathrm{J}$ (joint) & $\begin{array}{l}<40 \text { (improperly } \\
\text { taped) } \\
>300 \text { (properly } \\
\text { taped) }\end{array}$ & $\begin{array}{l}<40 \text { (improperly } \\
\text { taped) } \\
>300 \text { (properly } \\
\text { taped) }\end{array}$ & Class-1 & Low \\
\hline $\mathrm{K}$ & $>300$ & $>300$ & Class- 6 & High \\
\hline
\end{tabular}

\section{Figures}

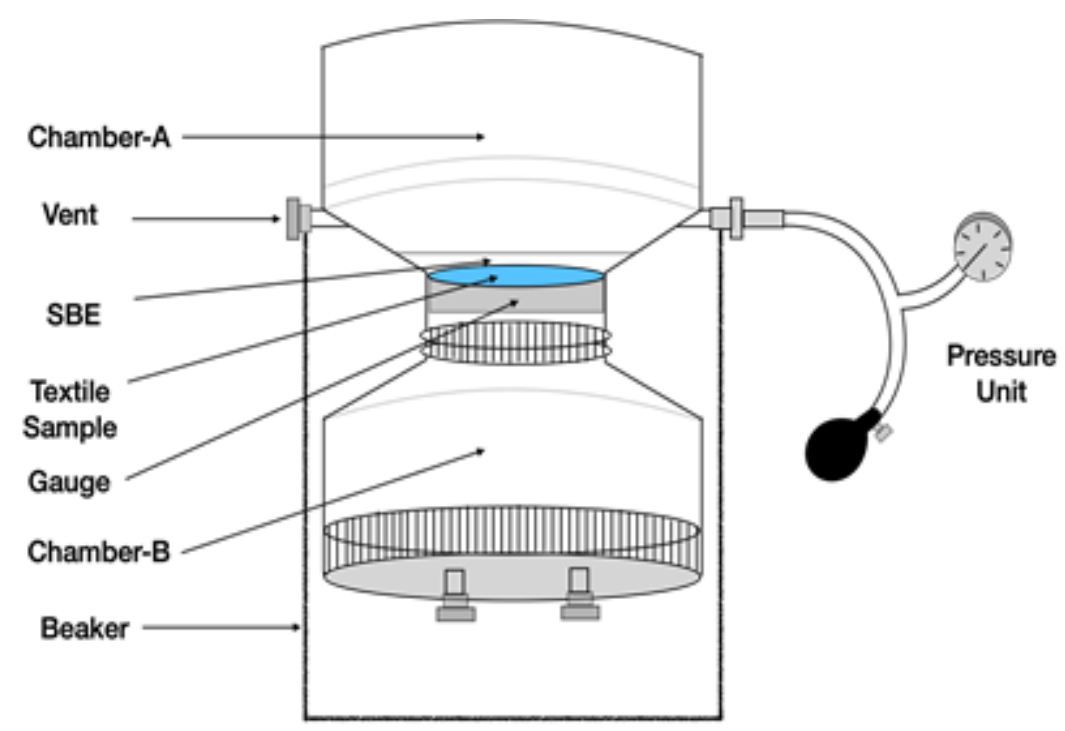

Figure 1 


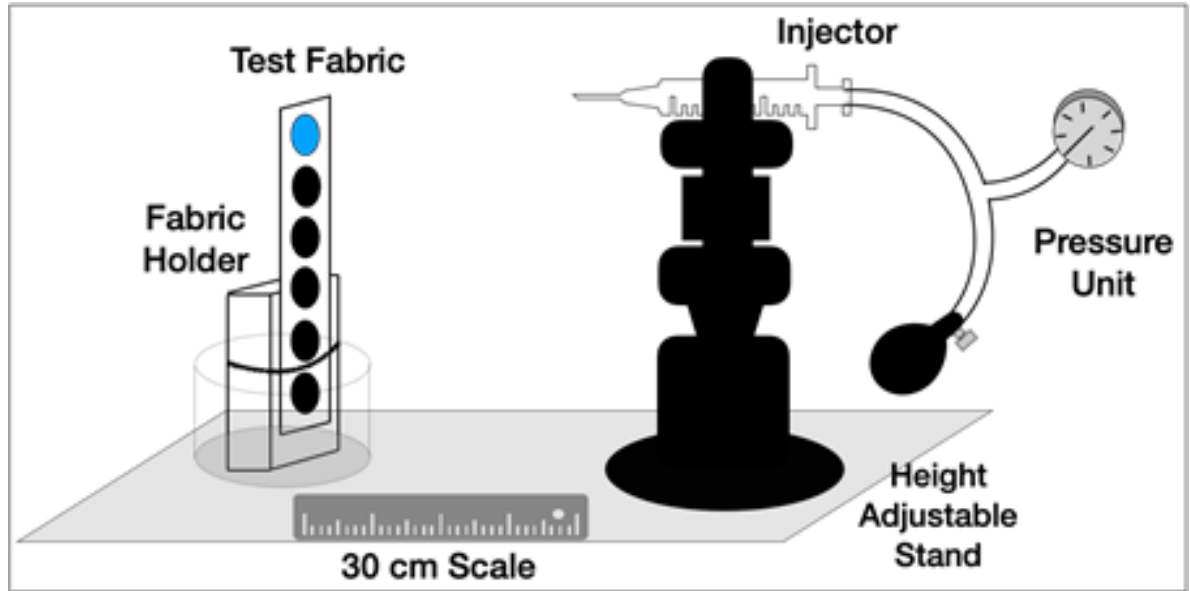

\section{Figure 2}

Laboratory simulated set-up for Splash Resistance Test on PPE fabric.

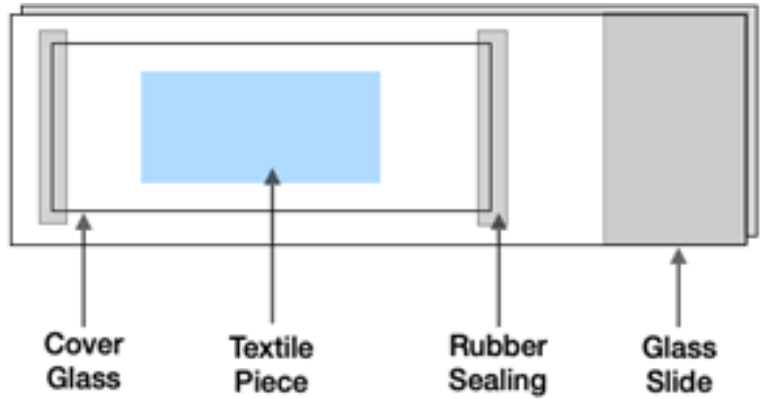

Figure 3

Preparation of slide for microscopic examination - PPE fabric sample sandwiched between glass slide and cover glass with the ends sealed with rubber cement.
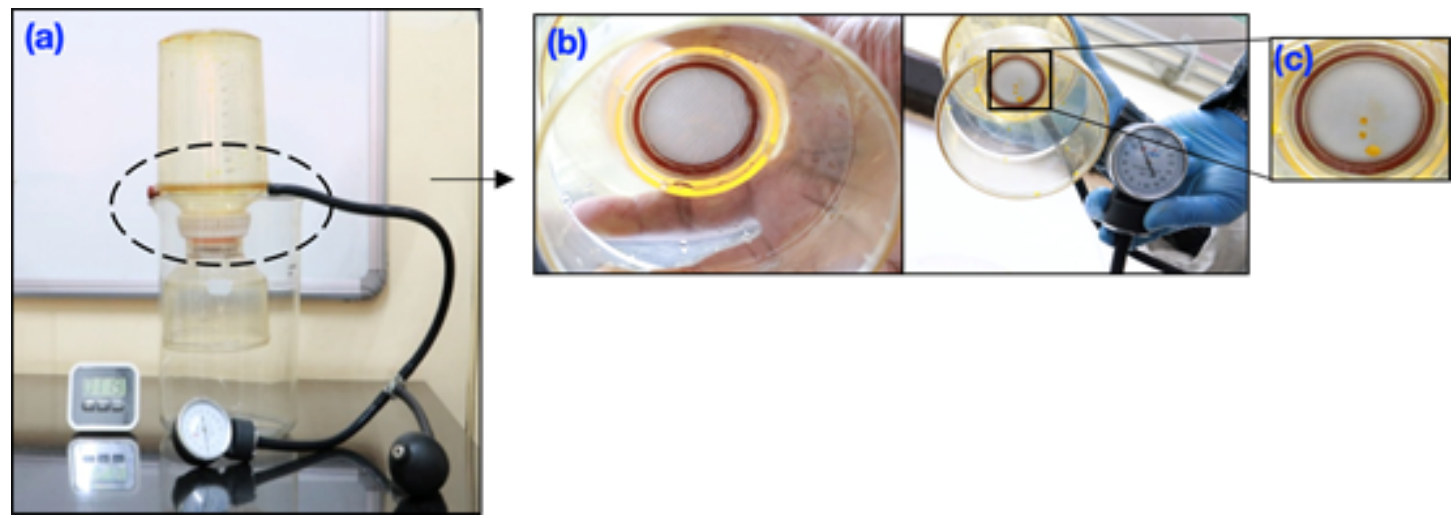

Figure 4

a) Complete Test Set-up for SBPRT (b) Lower side of the fabric mounted on a holder and (c) Visually observable droplets that penetrated through the fabric 

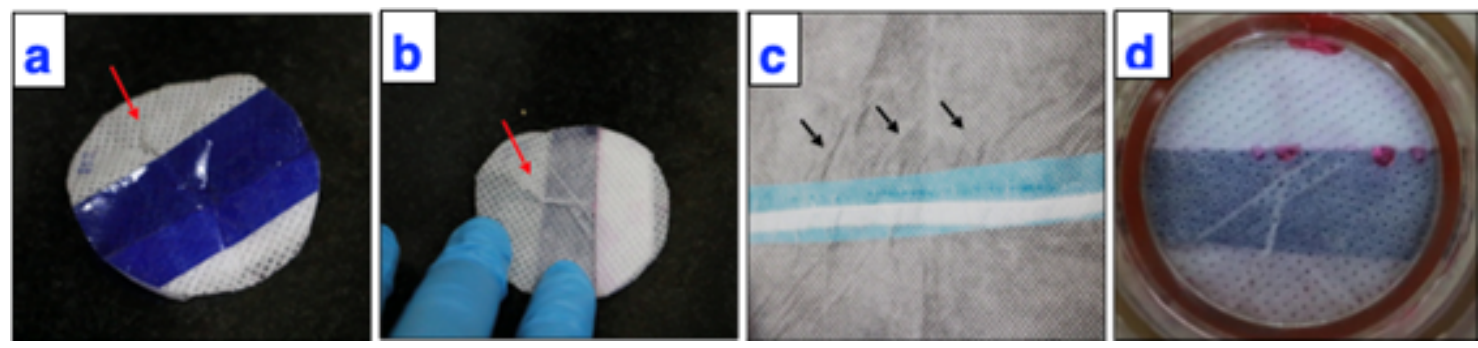

\section{Figure 5}

Fabric sample showing creases at the taped joints; (a) Front view of the joint (b) Back view of the joint (c) Close view of the joint (d) SB penetrated through the joint at $40 \mathrm{mmHg}$ applied fluid pressure

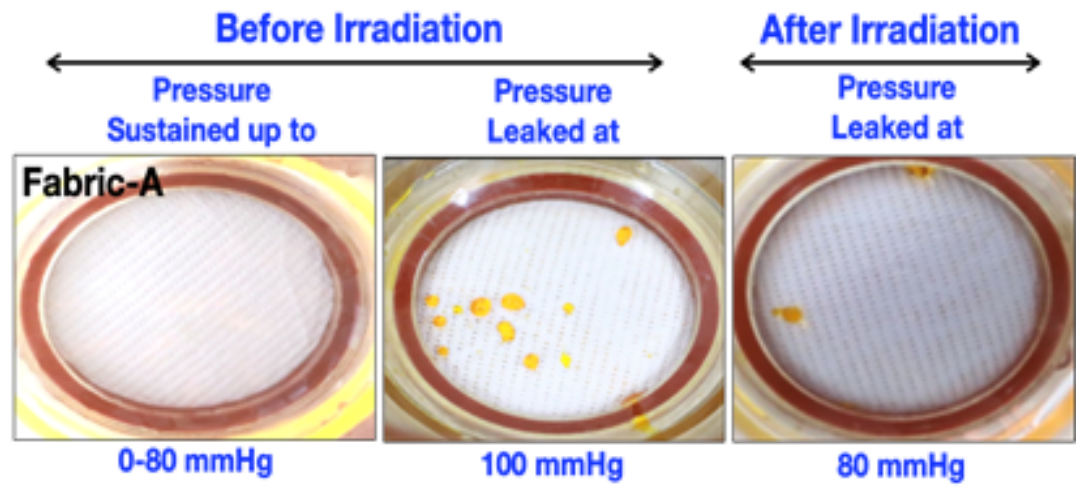

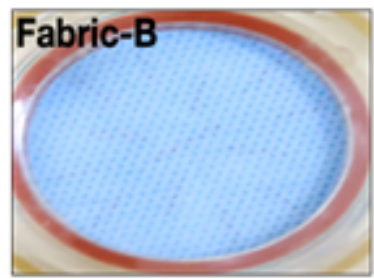

$0-40 \mathrm{mmHg}$

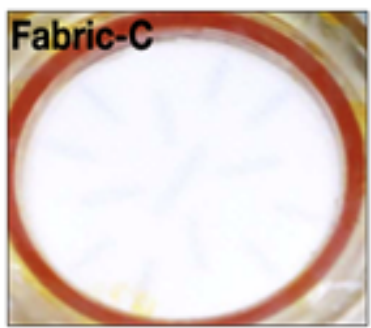

$0-300 \mathrm{mmHg}$

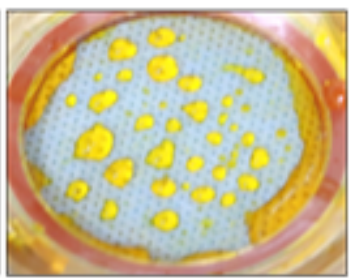

$60 \mathrm{mmHg}$

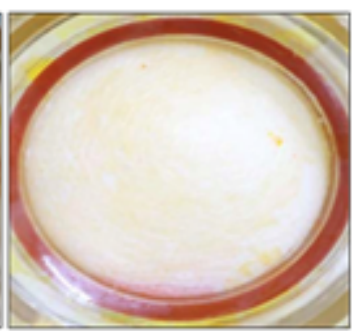

$300 \mathrm{mmHg}$
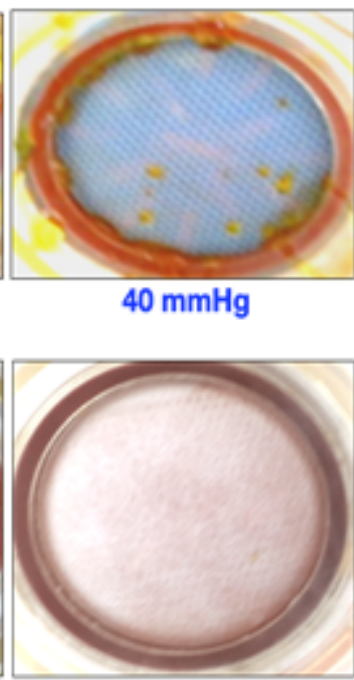

$300 \mathrm{mmHg}$

\section{Figure 6}

Visual examination of fluid penetration through test fabric at various pressure ranges. Left column shows no observed leakage, middle column shows the breaking pressure point at which fluid penetrated through the fabric and the last column shows breaking pressure points after radiation sterilization. 

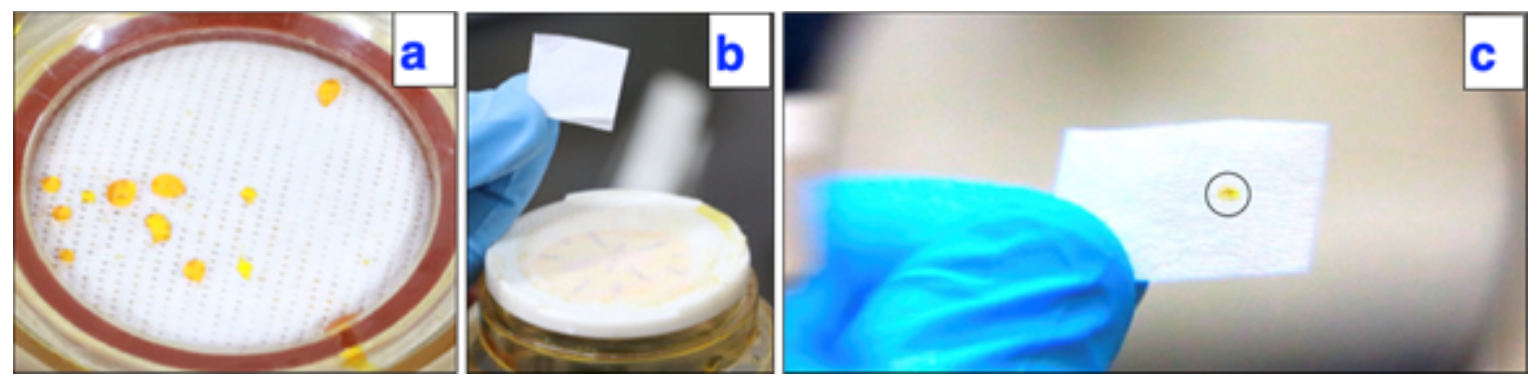

Figure 7

Illustration of three levels of detection of fluid penetration through the fabric (a) naked eye (b) swipe test with absorbent paper (c) Magnification with hand-lens.

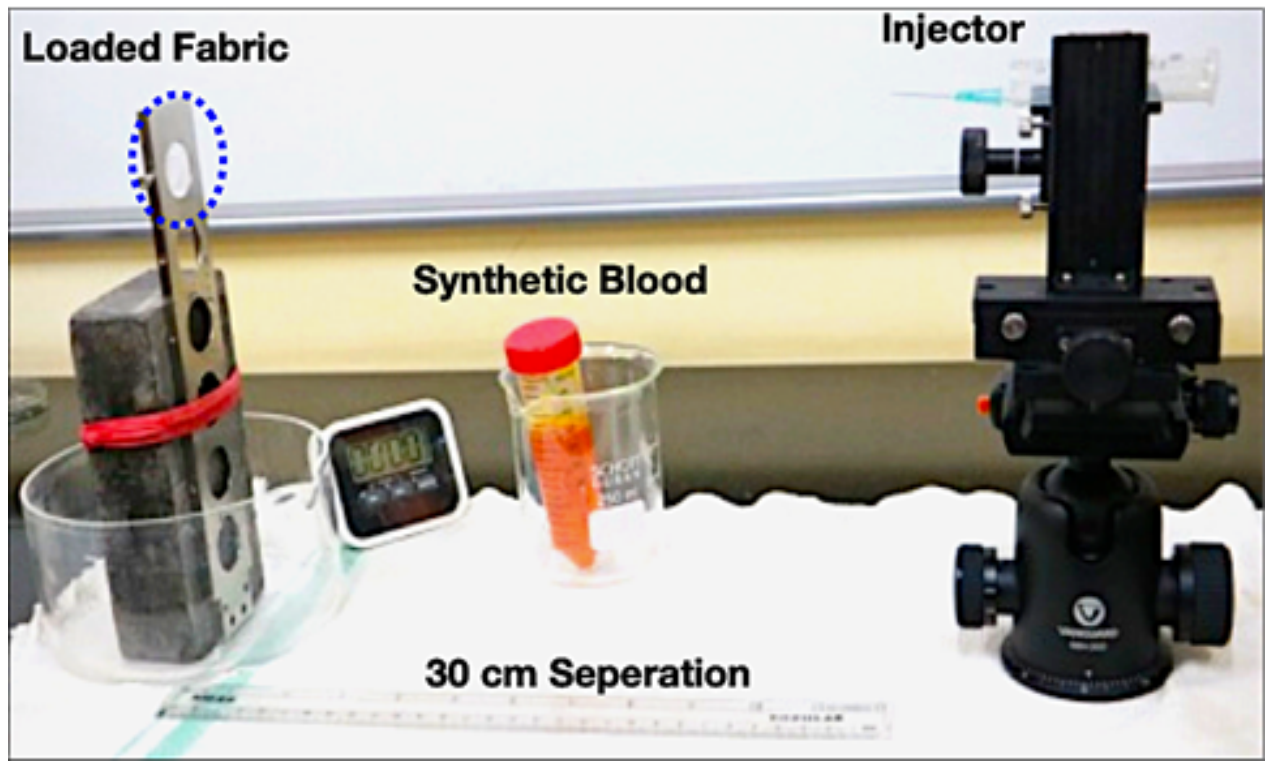

Figure 8

Test Set-up for Splash-Test showing the test fabric holder and the Synthetic blood injector
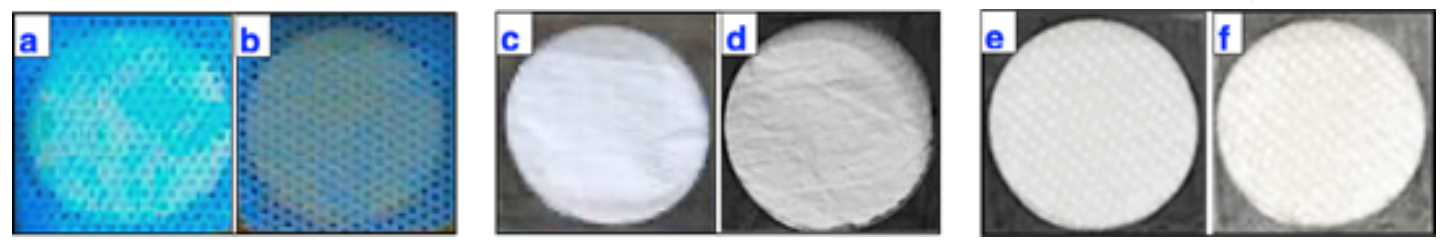

\section{Figure 9}

Back view of fabrics $-A, B$ and $C$ before and after splash test. All fabrics resisted penetration of fluid splashed at pressures of $280-300 \mathrm{mmHg}$.

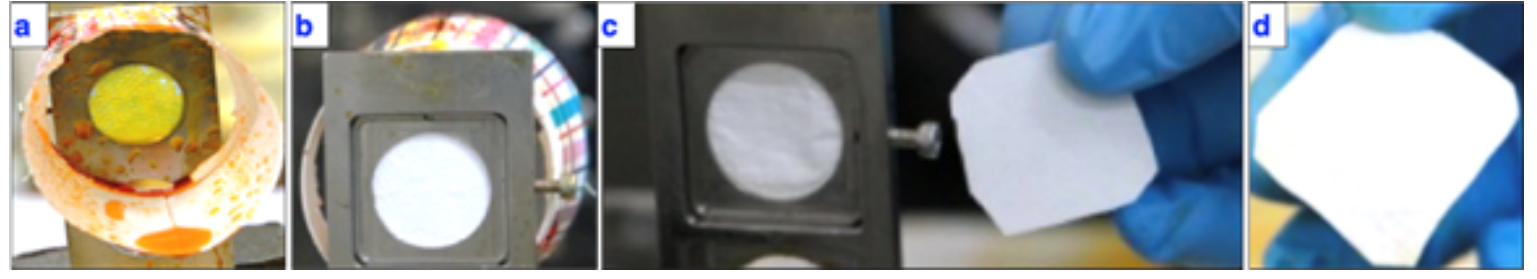




\section{Figure 10}

The detection levels for splash test: (a) Front view of fabric after splash (b) Back view of fabric after splash (c) Detection of leakage by swipe test with absorbent paper (d) Magnified view of the absorbent paper after swipe test.

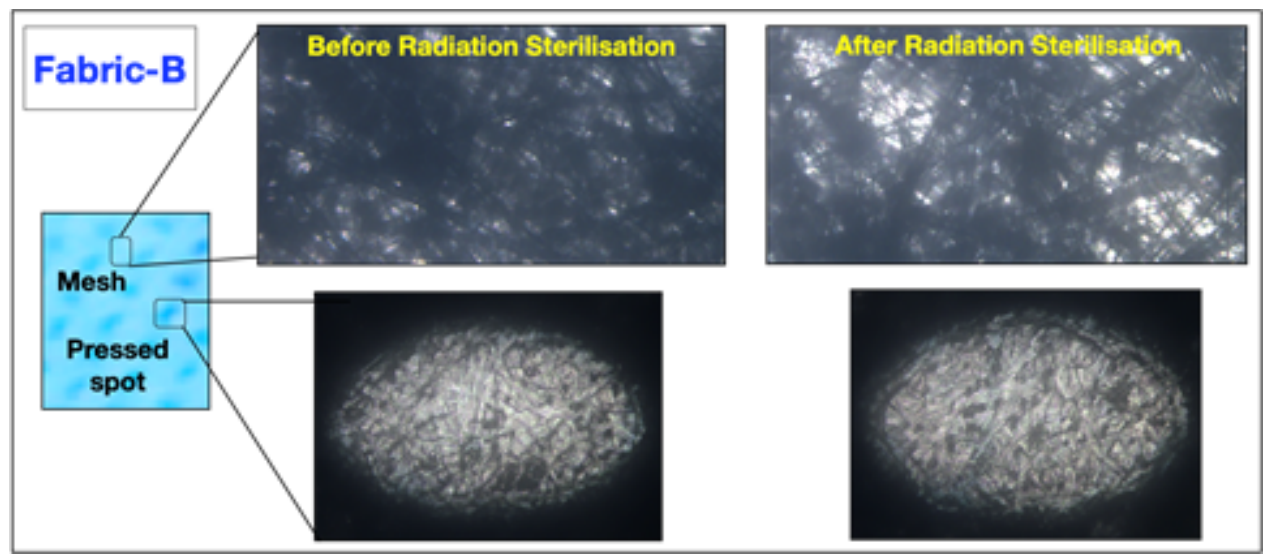

\section{Figure 11}

Microscopic (bright field) examination of fabric-B, at 100X magnification revealed that radiation sterilization increases the number and size of voids in the mesh region of the fabric, however no changes/deteriorations were observed in the pressed region, before and after radiation sterilization.

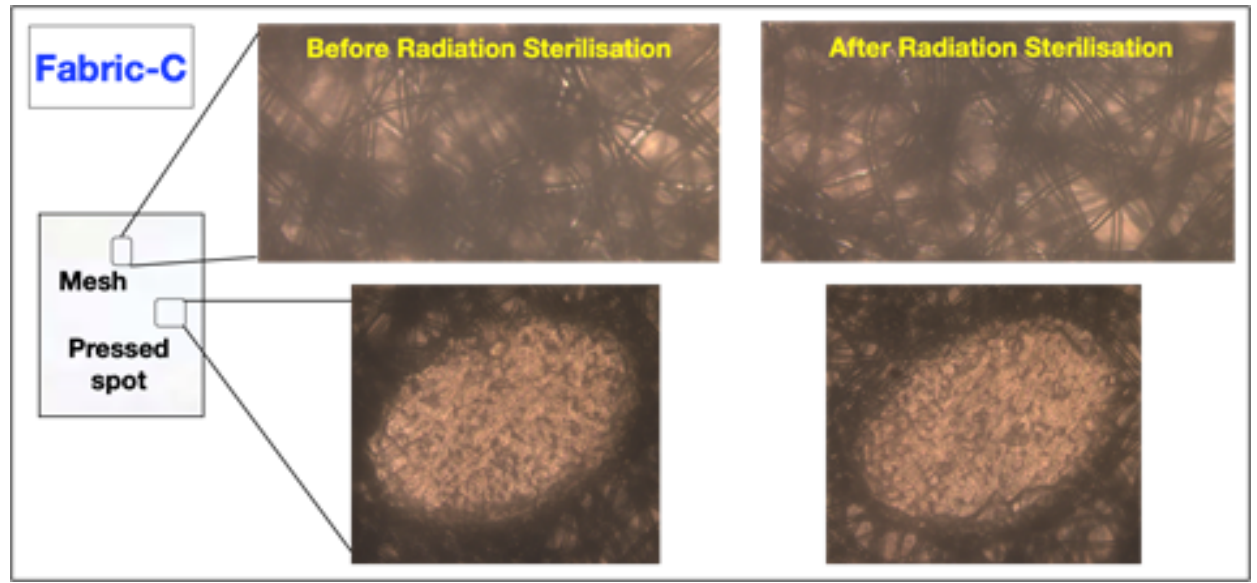

\section{Figure 12}

Microscopic (bright field) examination of fabric-C at 100X magnification showing no structural changes in mesh and pressed regions, before and after radiation sterilization. 